\title{
Evaluating the existence of structural change in the Brazilian term structure of interest rate: evidence based on Hansen"s cointegration models with structural break
}

\author{
Emerson F. Marçal \\ Sao Paulo School of Economics - FGV, CEMAP- FGV and Mackenzie University
}

\section{Pedro L. Valls Pereira}

Sao Paulo School of Economics - FGV and CEQEF-FGV

\begin{abstract}
This paper investigates whether there is evidence of structural change in the Brazilian term structure of interest rates. Multivariate cointegration techniques are used to verify this evidence. An econometric model is estimated which is a Vector Autoregressive Model with Error Correction Mechanism (VECM) with abrupt structural change formulated by Hansen [13]. Two datasets were analysed. The first one contains a nominal interest rate with maturity up to three years. The second data set focuses on maturity up to one year. The first data set focuses on a sample period from 1995 to 2010 and the second from 1998 to 2010. The frequency is monthly. The estimated models suggest the existence of structural change in the Brazilian term structure. It was possible to document the existence of multiple regimes using the technique for both databases. The risk premium for different spreads varied considerably during the earliest period of both samples and seemed to converge to stable and lower values at the end of the sample period. Long-term risk premiums seemed to converge to international standards, although the Brazilian term structure is still subject to liquidity problems for longer maturities.
\end{abstract}

JEL Code: G10, E43, C58

Key words: Term structure of interest rates; Structural change; VECM.

'The authors acknowledge the financial supprot from BNDES. The views expressed in this paper are those of the authors and do not reflect those of BNDES or its members. Both authors acknowledge the financial support from CNPq and FAPESP. . 


\section{Introduction}

A series of studies in recent years, conducted internationally and within Brazil, has sought to evaluate the validity of the Expectations Hypothesis (EH). The Expectations Hypothesis is based on the validity of a no-arbitrage condition between rates of various maturities. In the absence of risk and premium for liquidity and with organised and free markets, the value of the rate with the longest term should be equal to a weighted average of shortterm rates. With the consolidation of economic stability in Brazil, it has become possible to transact securities with a fixed yield in nominal terms for increasingly longer maturities. Thus, there is increasing interest in studies of properties existing in the Brazilian term structure and how these affect inflation and the gross domestic product, among other quantities. When analysing a longer period of time, it becomes difficult to postulate that the data generating process remains unaltered.

Research is being conducted to create economic models allowing various regimes over time to be considered to make data analysis richer and more precise. Data analysis regarding term interest presents various sources of potential inconstancy over time, such as the variance of the risk premium over time, temporal heteroscedasticity, and regime changes due to alterations in economic policy, among others. The goal of this study was to model the Brazilian term structure with multivariate cointegration techniques that allow for structural breakage and conditional heteroscedasticity.

The study of term structure based on multivariate models with cointegration was performed in international studies by Anderson, Hall and Granger [1], Engsted and Tanggaard [9], Johnson [18] and Pagan, Hall and Martin [24]. The results of the studies suggest that the spreads for the various rates are not stationary, which implies the violation of no-arbitrage conditions or the existence of non-stationary risk premiums. Marçal and Valls Pereira [23] showed that the results for Brazil are very similar to those obtained by the cited studies for other nations.

This study was inspired by the study by Hansen [13] on the American term structure. The author documented the presence of structural breakage in the mean and variation of American interest data. After controlling for this breakage, the author was no longer able to reject the hypothesis that the spreads - the difference in the interest rate between long and short maturities - are stationary. This conclusion was not obtained when analysing the case assuming processes without structural change.

The main conclusions of this study are the following: a) there is evidence of structural change in the Brazilian term structure and risk premiums vary for different periods; b) estimated models suggest that premiums fell sharply beginning in 2003 and began to converge to values obtained from 
international studies; c) the hypothesis that spreads for various maturities are stationary is not rejected in the estimated models in the recent period, suggesting that there is arbitrage in the Brazilian term structure over the long term.

This study is organised in the following way. In section 2 , a description of the Expectations Hypothesis is presented. In section 3, the econometric methodology used in the study is presented; that is, the multivariate models of cointegration are presented in the form proposed by Hansen [13]. In section 4, the database and the graphs and descriptive statistics for the data are presented. In section 5, the estimation results from the models are presented and discussed. In section 6 , a comparison of the results with those of the literature is presented. Finally, conclusions are presented.

\section{Expectations Hypothesis}

Defining $R_{t}^{m}$ as the logarithm of the annualised return paid for a longterm security of $m$ periods and $R_{t}^{n}$ as the logarithm of the annualised return paid for a short-term security of $n$ periods such that $n<m$, the spread $(m, n)-S_{t}^{m, n}-$ can be defined as $S_{t}^{m, n}=R_{t}^{m}-R_{t}^{n}$. The basic equation for modelling the term structure of interest rates is

$$
S_{t}^{m, n}=(1 / k) E_{t}\left[R_{t}^{n}+R_{t+i n}^{n}+\ldots+R_{t+i n}^{n}\right]+T_{t}^{m, n}
$$

where $E_{t}$ represents the expectation formed at $t, k=(m / n), i=1,2, . ., k$ and $T_{t}^{m, n}$ is the premium demanded by agents for opting for a longer-term strategy.

In principle, an investor can choose between two strategies: in the first, he or she holds the security of term $m$ until maturity and obtains the return of $R_{t}^{m}$. The other strategy consists of buying securities of term $n$ for $(m / n)$ consecutive periods. At equilibrium, equation (1) should be respected if agents arbitrate the differences in the rates, taking into account the premium and the expected value of short-term interest rates. Expectations are formed rationally. An open question regarding the expectations hypothesis has to do with the term of the premium. The discussion about its determinants is long standing and goes back, for example, to Keynes [19] and Hicks [14].

A review of how term risk was modelled from that period until the present day can be found in Shiller [31]. Cuthbertson and Nitzsche [6], on pages 494 to 498 , present the following typology for classifying the various ways in which the risk premium is modelled: I) Pure Expectations Hypothesis: in this version, the premium required is constant and equal to zero; II) Constant Risk Premium Expectations Hypothesis: in this version, 
the premium required is constant, different from zero, and equal for all maturities; III) Increasing Risk or Liquidity Premium Hypothesis: in this version, the premium is constant over time and greater for longer spreads; IV) Hypothesis of Variable Risk over time: in this version, the premium required by the agents varies over time; V) Segmented Market Hypothesis: in this version, the value of shares depends in some way on the stock of these available, and this has an influence on the spreads; and VI) Hypothesis of Constant Returns for Period of Loading: in this version, one should not compare securities of differing maturities but rather the return for each security of whatever maturity by loading these in the portfolio for a fixed period.

Models I to III are restricted in terms of generality; however, they are the most easily tested and implemented. Model IV is a general model, difficult to implement in the generic form as presented above. Model V offers a clue to some useful additional information to be incorporated into the analysis of term structure for interest rates if tests for the simpler models fail. Model VI, in fact, implies a certain scepticism regarding the expectations hypothesis and suggests that the tests should concentrate only on the returns for the securities of any maturity for a particular period. The expectations hypothesis can also be presented in the following form. By reordering the equation (1), one can arrive at

$$
R_{t}^{m}-R_{t}^{n}=\sum_{i=1}^{k-1}(1-(i / k)) E_{t}\left(\Delta^{n} R_{t+i n}^{n}\right)+T_{t}^{m, n}
$$

Equation (2) is the point of departure and fundamental reference for the analysis that follows. All the terms are defined above. The equation above suggests that with spreads discounted, the risk premium follows a stationary process to the extent that the term on the right should be stationary, whether observed from a theoretical or from the empirical point of view. Using the proposed methodology - Hansen [13] - it is possible to introduce into the econometric model a way of testing whether the risk premium $\left(T_{t}^{m}\right.$ ) varies over time and to obtain an estimate of how it varies. In this sense, the modelling proposed in this study that allows for the estimation of models with risk premiums that vary over time is, possibly, an advance in the Brazilian empirical literature.

\section{Econometric methodology}

The point of departure of the analysis is given by Johansen [15]:

São Paulo J.Math.Sci. 8, 2 (2014), 211-239 


$$
\Delta X_{t}=\Gamma_{1} \Delta X_{t-1}+\ldots+\Gamma_{k-1} \Delta X_{t-k+1}+\alpha\left[\begin{array}{ll}
\beta^{\prime} & \mu
\end{array}\right]\left[\begin{array}{c}
X_{t-1}^{\prime} \\
1
\end{array}\right]+\varepsilon_{t}
$$

where $\varepsilon_{t}$ are temporally uncorrelated random errors, $\Omega$ is the respective variance and $\left[\Gamma_{1}, \ldots \Gamma_{k-1}, \alpha, \beta, \mu\right]$ are the model parameters.

Although the model dynamics are quite rich and were explored in Johansen [15], this model possesses some important limitations, such as the temporal invariance of the parameters for both the conditional mean and the variance. There has been an attempt in the literature to generalise this model along various directions: to incorporate heteroscedasticity into the errors (Hansen[13] and Cavaliere et al. [4]) and nonlinearities into the fit (Gonzalo et al. [11], Kristensen and Rabhek [21] and Saikonnen [29]). Ripatti and Saikonenn [25] and Johansen and Mosconi [17] have sought to incorporate permanent changes into the deterministic terms.

3.1. The cointegration model with Hansen structural break. The point of departure is a VECM model with multiple regimes:

$$
\Delta X_{t}=\sum_{i=1}^{q} 1_{i, t}\left(\Gamma_{1, i} \Delta X_{t-1}+\ldots+\Gamma_{k-1, i} \Delta X_{t-k+1}+\alpha_{i} \widetilde{\beta}_{i}^{\prime} \widetilde{X}_{t-1}\right)+\varepsilon_{t}
$$

where $\varepsilon_{t}$ is a vector of variables with zero mean and finite variance, $q$ denotes the various regimes, $\widetilde{\beta}_{i}=\left[\begin{array}{ll}\beta & \mu_{i}\end{array}\right]$ and $\widetilde{X}_{t-1}=\left[\begin{array}{ll}X_{t-1} & 1_{i}\end{array}\right]$. The matrices $\left(\Gamma_{1,1}, \Gamma_{2,1}, \ldots, \Gamma_{k-1, q}, \alpha_{1}, \ldots, \alpha_{q}, \beta_{1}, \ldots, \beta_{q}\right)$ contain the model parameters, and $1_{i, t}$ is an indicator function that assumes a value of 1 when the date is in the period $t$ refers to the regime $i$ and zero otherwise. Model (4) permits for structural break for the short- and long-term parameters and for the risk premiums.

3.2. Estimation Techniques. The model given by (4) was estimated strictly following the algorithm proposed by Hansen [13]. The algorithm consists of a sequence of regressions of generalised least squares. At each step, there should be an increase in likelihood. The criterion for convergence is given by a minimum increase in likelihood after a series of iterations. The algorithm is initiated based on random values. To evaluate the robustness of the final result, the algorithm was run a few times to verify whether the criterion for convergence was satisfied around the same neighbourhood. Both algorithms were programmed in Matlab by the authors. 
3.3. Hypothesis Testing. The modelling strategy consists of the estimation of the models described in earlier sections and the evaluation of their suitability based on specification tests that evaluate hypotheses such as normality, heteroscedasticity and the presence of autocorrelation in the residuals. In particular, the presence of non-serially correlated residuals is of vital importance for the presence of non-biased estimators in the framework of Autoregressive Vectors. After the models were evaluated and chosen based on such criteria, we moved to testing hypotheses with some economic significance. In particular, we evaluated the hypothesis that held that cointegration vectors satisfy the restrictions suggested by the spreads. ${ }^{1}$

Once the number of cointegration relations in the system has been correctly determined, in general, various procedures for testing hypotheses on the parameters of the estimated model can be performed based on tests of the likelihood ratio. With the exception of parameters that involve nonlinearities, the remaining hypotheses can be formulated and tested based on procedures for the likelihood ratio, which have an asymptotically chisquared distribution with the respective degrees of freedom. A hypothesis that will be broadly investigated in this report has to do with the stationarity of spreads between interest rates for various maturities.

\section{Description of the database}

4.1. Database 1. The database analysed was collected at the site of BM\&F. It corresponds to the values of interest rate swap contracts for various maturities. The data are monthly and for the end of the period (Figure 1). The period of the sample begins in January 1998 and runs until December 2011. The peaks analysed are for 1, 6, 12, 24 and 36 months.

As a general trend, there seems to be a progressive drop in nominal rates for various maturities. At the end of the sample, all rates were floating around the value of ten percent. Historical peaks are found in 1999 during the period that followed the devaluation of 1999. Another period of high rates took place during 2002, principally for longer maturities.

Apparently, the variation in the volatility of the series was greater at the beginning of the sample, principally during the years 1998 and 1999 (Figure 2 ). The correlogram of the spreads suggests the existence of some memory (Figure 5). This can be seen both in the graphic depicting this period and from the temporal correlations. An unusual finding is that the higher-order correlations fall almost monotonically until the correlation of the fifth order,

\footnotetext{
${ }^{1}$ We opted to determine the number of cointegration vectors present in each system based on economic arguments and not based on a specific test because, except for the traditional case given by (4), inferring the number of cointegration relations can become extremely complex.
} 
Evaluating the existence of structural change in the Brazilian term structure of interest rate: evidence based on Hansen's cointegration models with structural break

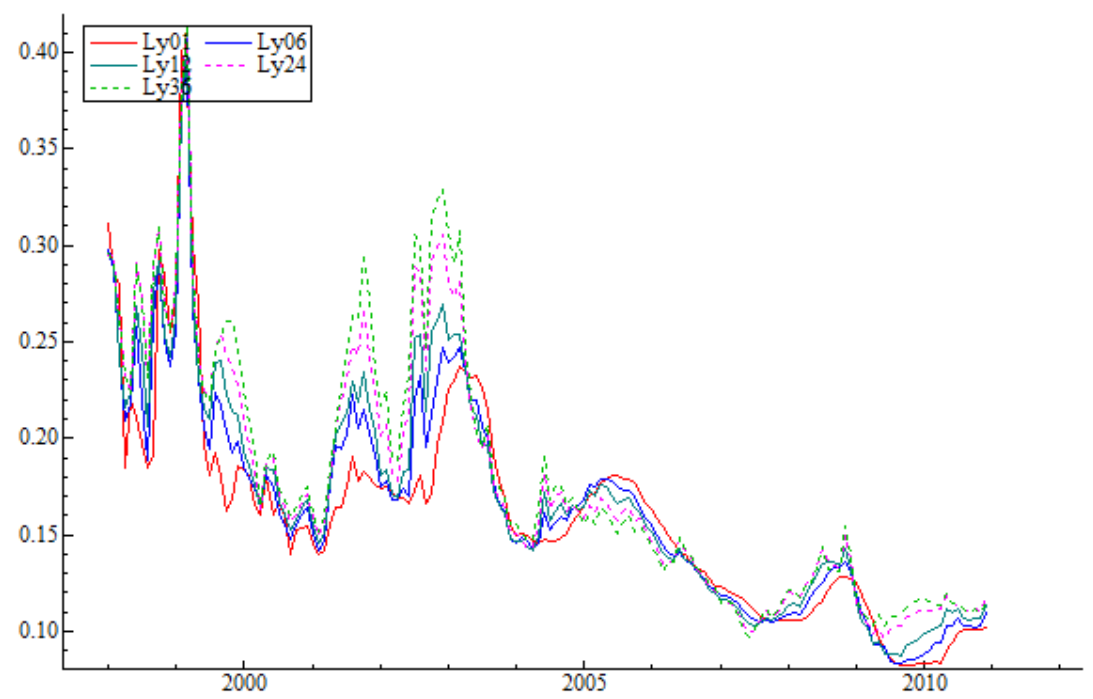

FiguRE 1. Evolution of rates for various maturities

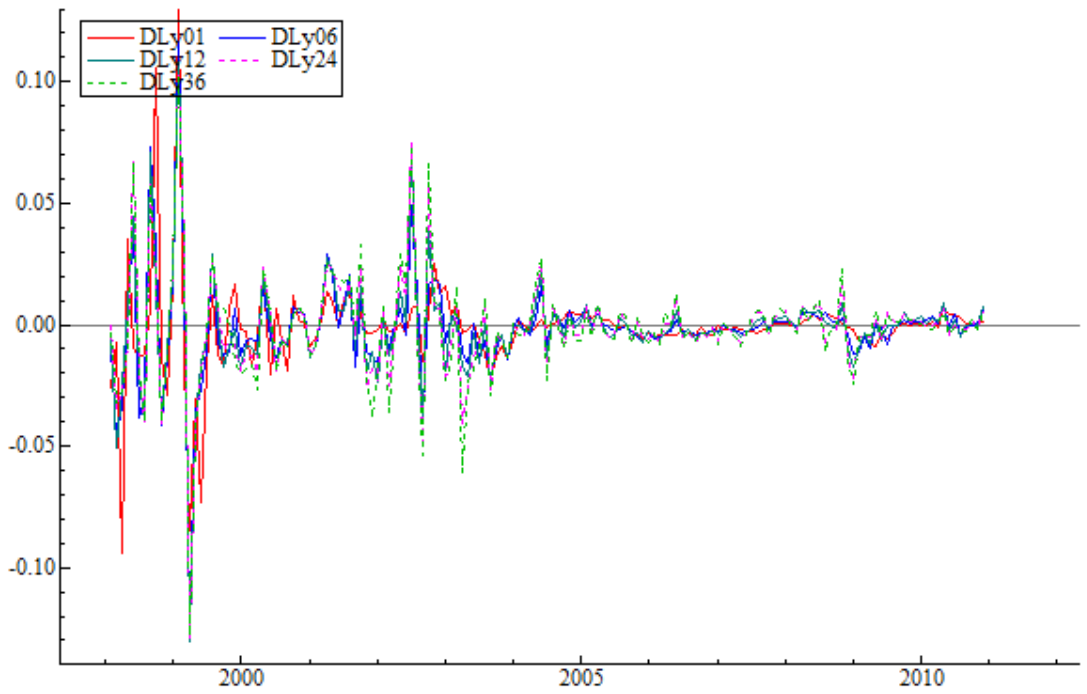

FiguRE 2. Evolution of the first difference for various maturities. 


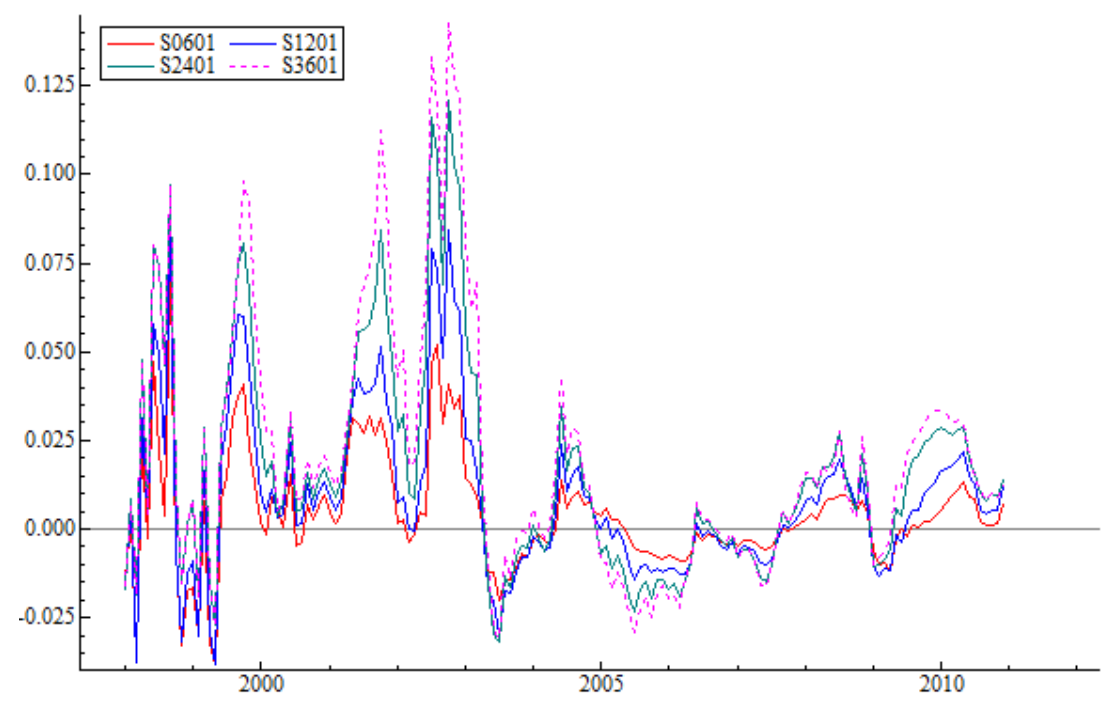

FiguRE 3. Evolution of spreads based on a one-month rate

more or less, and then return to being significant at a higher order. The correlograms of the first differences show low values for correlations (Figure 4)

4.1.1. Database 2. A second database was also analysed. This consisted of interest rate swap contracts at the $\mathrm{BM} \& \mathrm{~F}$, and the database was collected together with the Central Bank. The sample began in January 1996 and ended in December 2010. However, the peaks are limited to 1, 2, 3, 6 and 12 months because longer peaks with the proper liquidity are only available for the most recent period. A trend toward a drop in rate over the long term is also observed (Figure 6). The evolution of the variation in the rates logarithm (Figure 7) suggests greater volatility at the beginning of the sample compared with the end of the sample.

The evolution of spreads is shown in Figure 8, and there is apparently more than one regime in the data. The correlogram for the spreads, with the peak based on the one-month rate, suggests that there is a low memory for short peaks (60-30 and 90-30) and a greater memory for longer peaks (180-30 and 360-30). These results suggest that there is stronger arbitrage for shorter spreads, while greater persistence in the longer spreads suggests that the term risk varies over time and has greater persistence. 

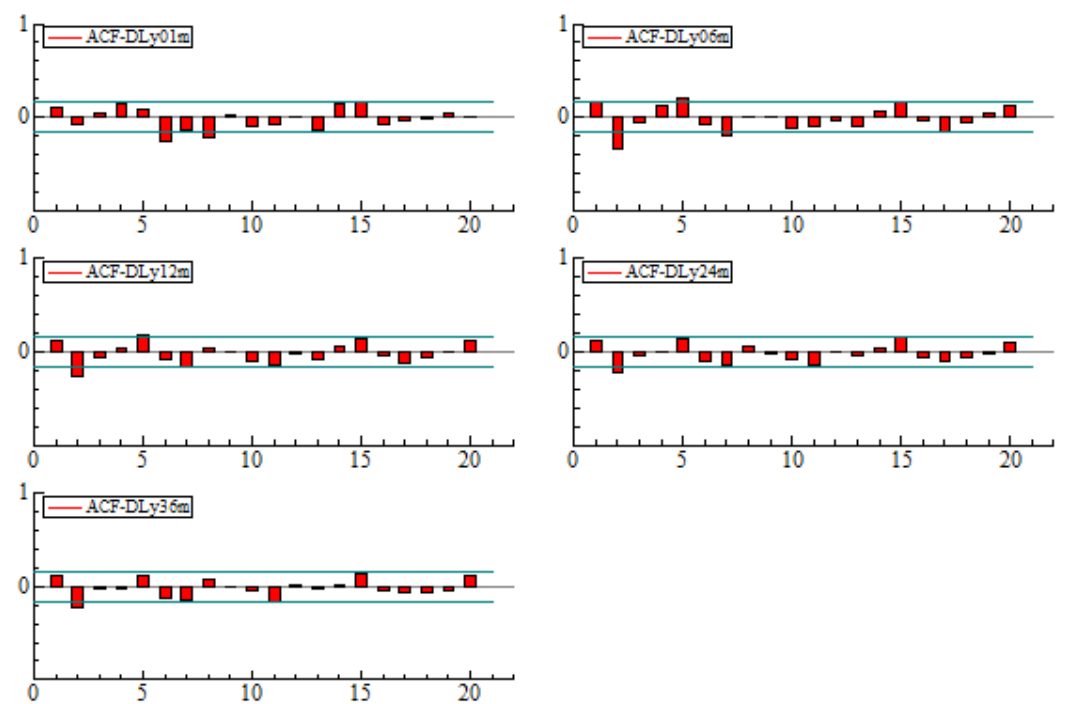

FiguRE 4. Correlogram of the first difference of the logarithm of rates.
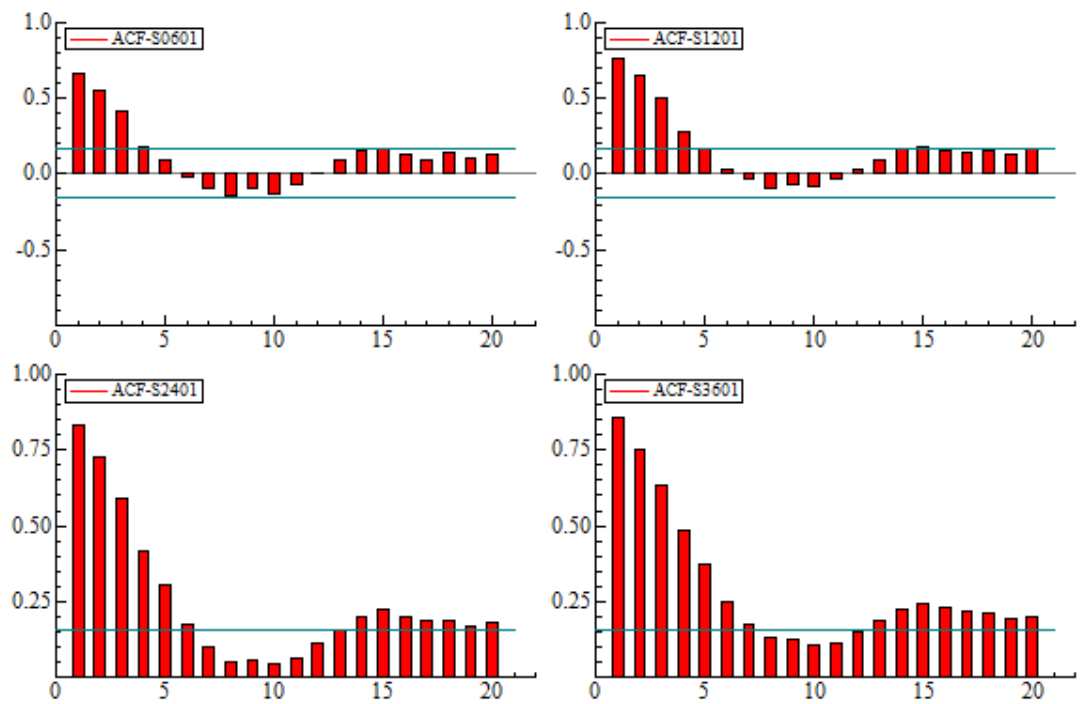

FiguRE 5. Correlogram of spreads based on a one-month spread. 


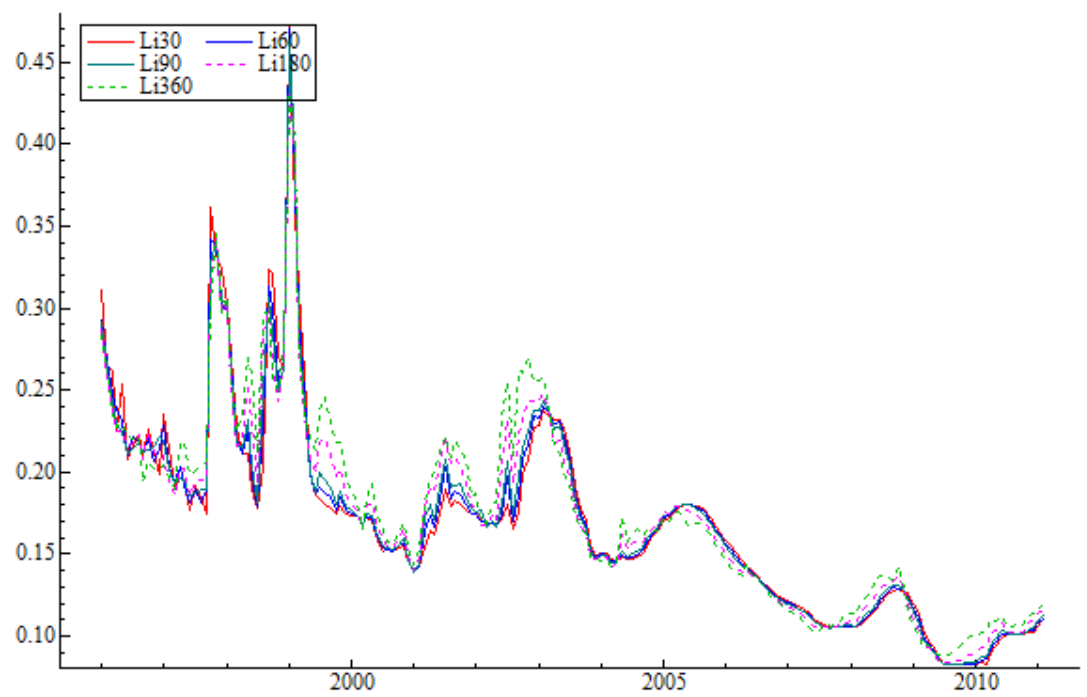

FigURE 6. Evolution of rates for various maturities.

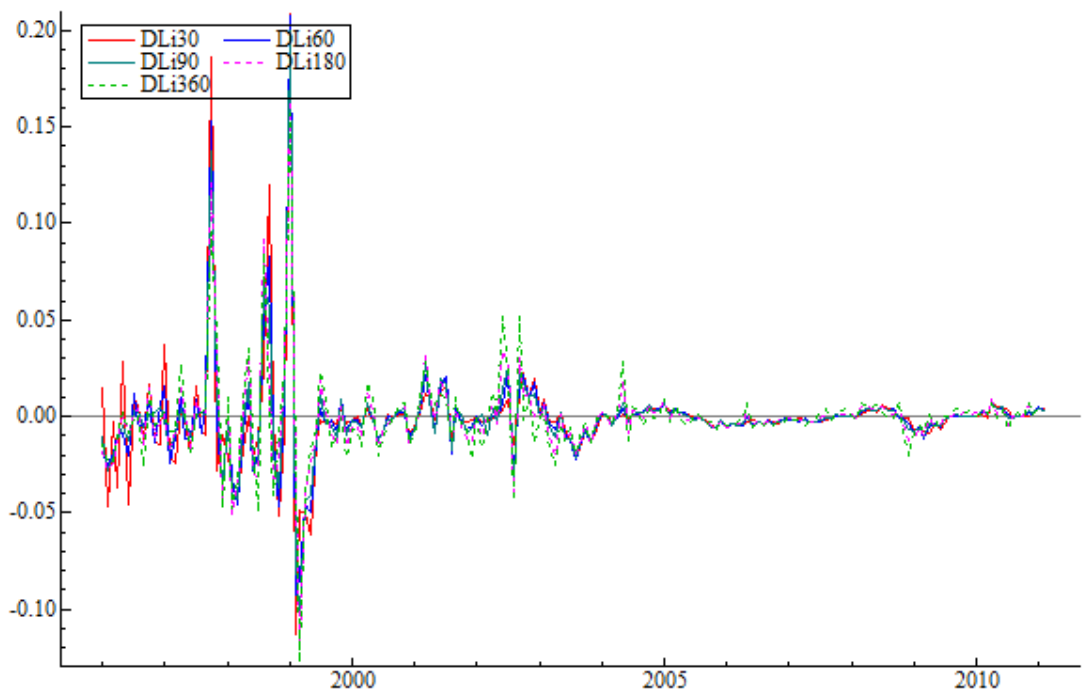

Figure 7. Evolution of rates for various maturities 


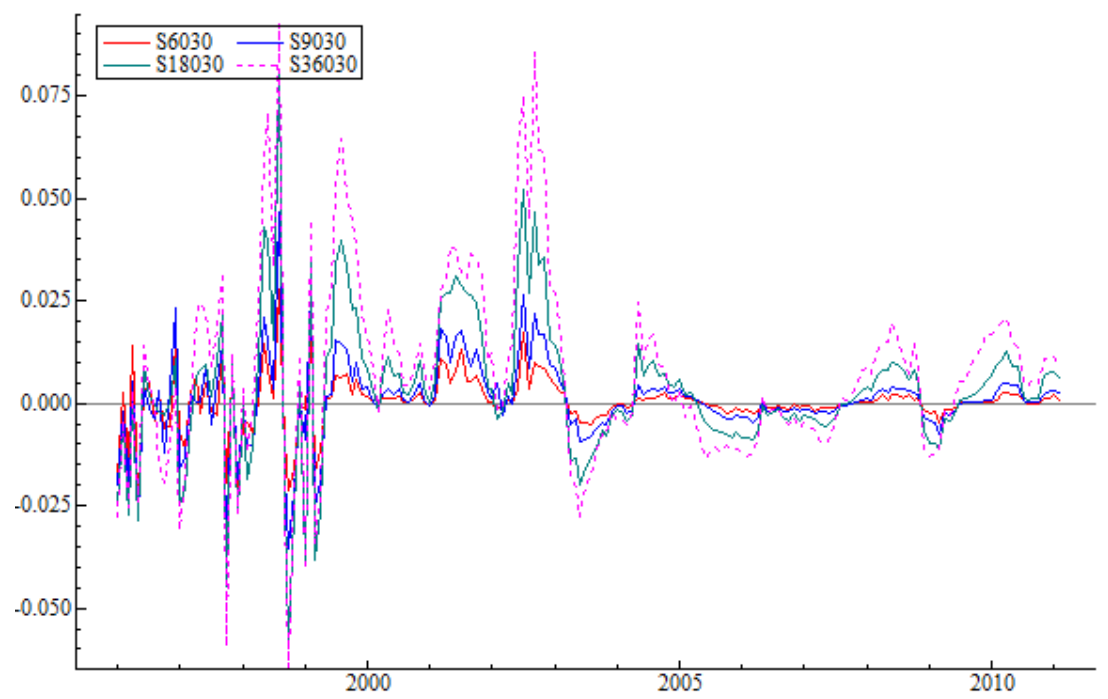

FigURE 8. Evolution of rates for various maturities.
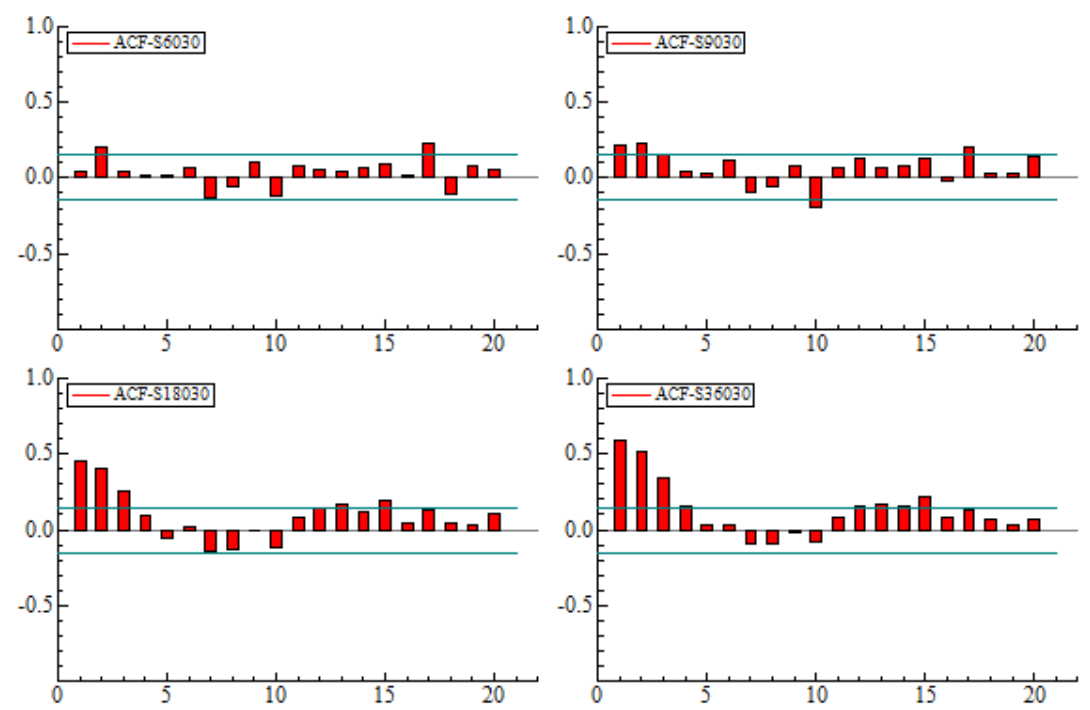

FiguRE 9. Correlogram for spreads for various maturities 

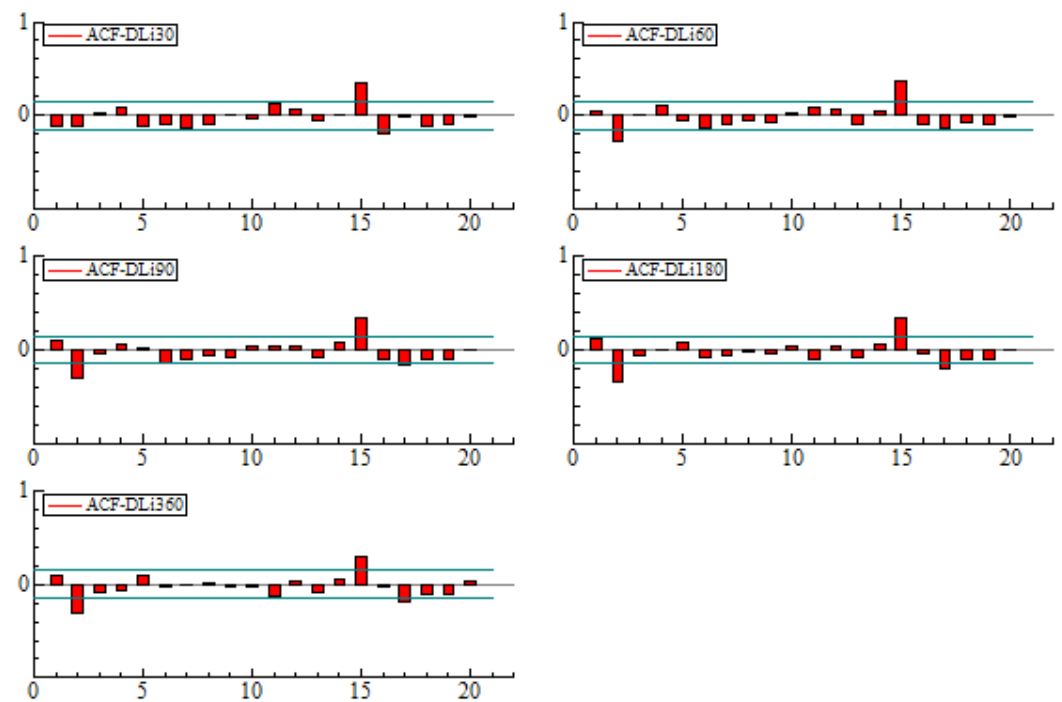

Figure 10. Correlogram for spreads for various maturities.

\section{Results Obtained}

In this section, the results estimated for the two databases described above are presented. First, we present the results of the typical model without structural break of any kind, as proposed in Johansen [15]. We present the results of the specification tests to evaluate to what degree the models can be considered good approximations of the data. Then we present the estimate results for the models proposed by Hansen [13] and evaluate to what degree these models prove to be better at describing the databases.

\subsection{Database 1.}

5.1.1. Traditional Model, Johansen [15]. We initially estimated a VECM with seven lags to model rates for 1, 6, 12, 24 and 36 months. The criterion for choosing these peaks was to guarantee the presence of rates that could be interpreted as short-, medium- and long-term. Term contracts with prefixed rates and maturities of more than a decade, common outside Brazil, are still rare in Brazil. Thus, a peak of 3 years can be considered long term in the context of the present conditions of the Brazilian economy. 
Evaluating the existence of structural change in the Brazilian term structure of interest rate: evidence based on Hansen's cointegration models with structural break

TABLE 1. Specification tests for the VECM model with constant and 7 lags

\begin{tabular}{|c|c|c|c|c|c|}
\hline Equation & 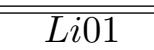 & $\overline{\mathrm{Li06}}$ & $\overline{L i 12}$ & 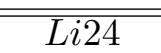 & $\overline{L i 36}$ \\
\hline 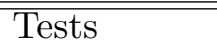 & \multicolumn{5}{|c|}{ Autocorrelation test order 1- 7} \\
\hline Distribution & $\mathrm{F}(7,106)$ & $\mathrm{F}(7,106)$ & $\mathrm{F}(7,106)$ & $\mathrm{F}(7,106)$ & $\mathrm{F}(7,106)$ \\
\hline Statistics & 1.3344 & 0.546 & 0.5716 & 1.2593 & 2.0063 \\
\hline p-value & {$[0.9660]$} & [0.9293] & [0.7350] & {$[0.7490]$} & {$[0.7582]$} \\
\hline Tests & \multicolumn{5}{|c|}{ Portmanteau (12) } \\
\hline Distribution & $\chi^{2}(5)$ & $\chi^{2}(5)$ & $\chi^{2}(5)$ & $\chi^{2}(5)$ & $\chi^{2}(5)$ \\
\hline Statistics & 6.0946 & 11.001 & 14.96 & 19.639 & 20.213 \\
\hline p-value & {$[0.2971]$} & $0.0514]$ & [0.0105] & {$[0.0015]$} & [0.0011] \\
\hline Tests & \multicolumn{5}{|c|}{ ARCH test - order 1 to 7} \\
\hline Distribution & $\mathrm{F}(7,135)$ & $\mathrm{F}(7,135)$ & $\mathrm{F}(7,135)$ & $\mathrm{F}(7,135)$ & $\mathrm{F}(7,135)$ \\
\hline Statistics & 3.1699 & 3.0641 & 4.1275 & 4.7356 & 5.5815 \\
\hline p-value & {$[0.0039]$} & {$[0.0050]$} & {$[0.0004]$} & {$[0.0001]$} & {$[0.0000]$} \\
\hline Tests & \multicolumn{5}{|c|}{ Heteroscedasticity Test } \\
\hline Distribution & $\mathrm{F}(81,67)$ & $\mathrm{F}(81,67)$ & $\mathrm{F}(81,67)$ & $\mathrm{F}(81,67)$ & $\mathrm{F}(81,67)$ \\
\hline Statistics & 4.0022 & 4.0476 & 3.9348 & 4.2091 & 4.5804 \\
\hline $\mathrm{p}$-value & {$[0.0000]$} & {$[0.0000]$} & 0.0000 & 0.0000 & [0.0000] \\
\hline Tests & \multicolumn{5}{|c|}{ Normality Test } \\
\hline Distribution & $\chi^{2}(2)$ & $\chi^{2}(2)$ & $\chi^{2}(2)$ & $\chi^{2}(2)$ & $\chi^{2}(2)$ \\
\hline Statistics & 21.418 & 22.317 & 30.522 & 31.926 & 24.068 \\
\hline $\mathrm{p}$-value & {$[0.0000]$} & [0.0000] & [0.0000] & {$[0.0000]$} & [0.0000] \\
\hline
\end{tabular}

Table 1 shows the results of the specification tests for the estimated model. There is strong evidence for the presence of non-normal and heteroscedastic residuals, a typical characteristic for data from Finances (Tsay [34]). One problem, however, draws our attention: the possible presence of serial autocorrelation in the residuals, which would make the estimates for the model parameters inconsistent. The problem seems to be more serious for longer-term equations, particularly the rate for 24 and 36 months based on the Portmanteau test. It is worth emphasising that the model estimated with 7 lags implies a high number of parameters to be estimated relative to the size of the sample (14 years with monthly data). This can distort the results in some way. 
TABLE 2. Johansen cointegration tests

\begin{tabular}{|c|c|c|c|c|c|}
\hline \hline Rank & Eigenvalue & Trace Test & p-value & $\begin{array}{c}\text { Maximum } \\
\text { Eigenvalue } \\
\text { Test }\end{array}$ \\
\hline 0 & 0.289 & 109.91 & {$[0.000]$} & 50.72 & {$[0.000]$} \\
\hline 1 & 0.177 & 59.19 & {$[0.015]$} & 28.97 & {$[0.042]$} \\
\hline 2 & 0.108 & 30.22 & {$[0.157]$} & 16.99 & {$[0.242]$} \\
\hline 3 & 0.058 & 13.23 & {$[0.354]$} & 8.85 & {$[0.462]$} \\
\hline 4 & 0.029 & 4.38 & {$[0.371]$} & 4.38 & {$[0.371]$} \\
\hline
\end{tabular}

Table 2 presents the results of the Johansen tests for cointegration for the system that contains the rates from database 1 . There is evidence of a cointegration vector for the trace statistic at a level of $1 \%$ and two vectors at a level of significance of $5 \%$ through maximum eigenvalue statistics. The Johansen procedure possesses low power, and because the estimated system has a larger number of parameters, it is difficult to state to what degree the results are due to the fact that there are not four cointegration vectors or whether it is a problem of a small sample. ${ }^{2}$

Table 3 contains the results of the test of the hypothesis that evaluates whether the cointegration vectors are given by the spreads. It was assumed that the number of cointegration relations is equal to 4 . If this hypothesis is correct, the test statistic has an asymptotic chi-squared distribution with four degrees of freedom. The null hypothesis is accepted loosely with a p-value of $27.12 \%$.

5.1.2. Hansen Model [13]. We estimated the Hansen model [13] for the data from database 1 . Because there is evidence of heteroscedasticity in the residuals, we opted for estimating a VECM whose pattern of heteroscedasticity is given by the DCC-GARCH multivariate model of volatility proposed by Engle [8]. The graph of the estimated volatilities for the various equations is presented in Figure 11. The highest levels of volatility are concentrated from the beginning of the sample until 2005. Beginning in 2005 , the level of volatility falls sharply for all rates. There is an increase

\footnotetext{
${ }^{2}$ The existence of four cointegration vectors would imply the existence of arbitrage between the various long-term rates and a stationary risk premium for all maturities
} 
Evaluating the existence of structural change in the Brazilian term structure of interest rate: evidence based on Hansen's cointegration models with structural break

TABLE 3. Results of the test of the hypothesis concerning cointegration space

\begin{tabular}{|c|c|c|c|c|c|c|}
\hline \multicolumn{7}{|c|}{ Johansen } \\
\hline$\overline{\text { Statistics }}$ & \multicolumn{6}{|l|}{ (5.16 } \\
\hline Degree of Freedom & \multicolumn{6}{|c|}{4} \\
\hline Distribution & \multicolumn{6}{|c|}{ Chi-square } \\
\hline p-value & \multicolumn{6}{|c|}{$27.12 \%$} \\
\hline \multicolumn{7}{|c|}{ Estimated Parameters } \\
\hline \multicolumn{7}{|c|}{ Regime 1} \\
\hline & $\overline{L i 01}$ & Li06 & $\overline{L i 12}$ & $\overline{L i 24}$ & $\overline{L i 36}$ & Constant \\
\hline Vector 1 & 1 & 0 & 0 & 0 & -1 & $1.99 \%$ \\
\hline Vector 2 & 1 & 0 & 0 & -1 & 0 & $1.62 \%$ \\
\hline Vector 3 & 1 & 0 & -1 & 0 & 0 & $0.92 \%$ \\
\hline Vector 4 & 1 & -1 & 0 & 0 & 0 & $0.47 \%$ \\
\hline \multicolumn{7}{|c|}{ Load Matrix } \\
\hline Equation 1 & 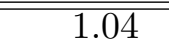 & $\overline{-1.62}$ & $\overline{1.40}$ & $\overline{-1.88}$ & & \\
\hline Equation 2 & 0.75 & -0.77 & -0.14 & -0.41 & & \\
\hline Equation 3 & 0.81 & -1.05 & 0.45 & -0.77 & & \\
\hline Equation 4 & 1.01 & -1.52 & 1.35 & -1.65 & & \\
\hline Equation 5 & 1.29 & -2.00 & 1.80 & -2.08 & & \\
\hline
\end{tabular}

in volatility at the end of the sample, most probably due to the sub-prime crisis in 2008. The increase in volatility was very modest. The highest levels of volatility were found for the longer maturities.

Table 4 presents the various estimated specifications for the data from database 1. The general model is that from number 4 . The other models present some additional restrictions to the initial model, and all of them were embedded. Model 1 gave the greatest number of restrictions. We allowed three distinct regimes. The first began at the beginning of the sample and ended in 2002:12. The second began in 2003:1 and ended in 2006:12. The third regime began in 2007:1 and ended at the end of the sample in 2010:12.

The tests reported in Table 5 indicate that model 2 would be a good simplification of the general model. In model 2 , the cointegration vectors are given by the spreads in all of the regimes, and the long-term premiums are constant between the regimes. Nevertheless, the load matrix varies between 


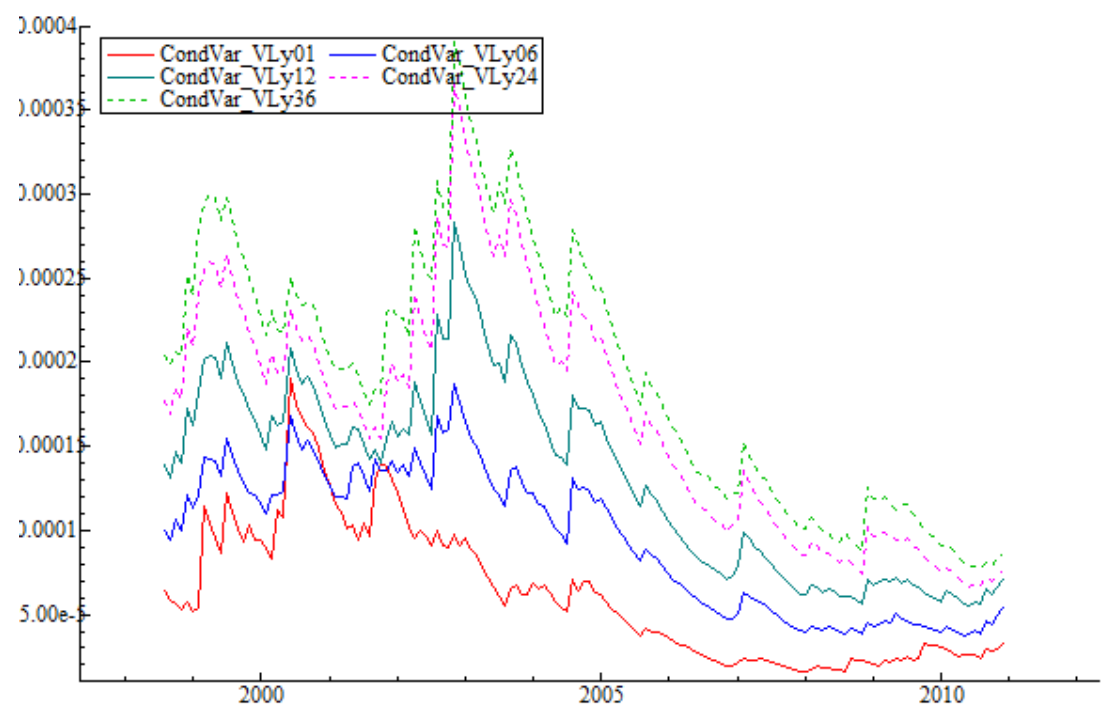

FIGURE 11. Estimated volatility of the clashes of various rates.

TABLE 4. Description of the estimated specifications for the Hansen model - Database 01

\begin{tabular}{|c|c|c|c|c|c|}
\hline \hline Model & $\begin{array}{c}\text { C.I. } \\
\text { Vectors: }\end{array}$ & Premium & $\begin{array}{c}\text { Load } \\
\text { Matrix }\end{array}$ & $\begin{array}{c}\text { Log } \\
\text { Likelihood }\end{array}$ & $\begin{array}{c}\text { Number of } \\
\text { Parameters }\end{array}$ \\
\hline 1 & spreads & $\begin{array}{c}\text { equal } \\
\text { between } \\
\text { regimes }\end{array}$ & $\begin{array}{c}\text { equal } \\
\text { between } \\
\text { regimes }\end{array}$ & 3869.02 & 174 \\
\hline 2 & spreads & $\begin{array}{c}\text { equal } \\
\text { between } \\
\text { regimes }\end{array}$ & unrestricted & 3945.93 & 214 \\
\hline 3 & spreads & unrestricted & unrestricted & 3953.69 & 222 \\
\hline 4 & unrestricted & unrestricted & unrestricted & 3960.20 & 234 \\
\hline \hline
\end{tabular}

the regimes; that is, there is structural change. Finally, Table 6 presents the values of the estimated parameters for the preferred specification. 
Evaluating the existence of structural change in the Brazilian term structure of interest rate:

evidence based on Hansen's cointegration models with structural break

TABLE 5. Tests of hypotheses used to evaluate simplifications of the estimated models - Database 1

\begin{tabular}{ccccccc}
\hline \hline Model & \multicolumn{2}{c}{ Mi against M2 } & \multicolumn{3}{c}{ Mi against M3 } \\
\hline$i$ & Stats. & D. F. & p-value & Statistics & D. F. & p-value \\
\hline \hline 1 & 153.81 & 40 & $0.00 \%$ & 169.33 & 48 & $0.00 \%$ \\
2 & & & & 15.52 & 8 & $4.98 \%$ \\
\hline \hline
\end{tabular}

\begin{tabular}{cccc}
\hline \hline Model & \multicolumn{3}{c}{ Mi against M4 } \\
\hline$i$ & Statistics & D. F. & p-value \\
& & & \\
\hline 1 & 182.35 & 60 & $0.00 \%$ \\
2 & 28.54 & 20 & $9.72 \%$ \\
3 & 13.02 & 12 & $36.75 \%$ \\
\hline
\end{tabular}

\subsection{Database 2.}

5.2.1. Traditional Johansen Model [15]. The traditional Johansen analysis was also performed for the data from database 2 , which contains the rates for $1,2,3,6$, and 12 months. We estimated a model with 7 lags. The results of the specification tests for the model are presented in Table 7 . Depending on the test analysed, there is evidence of serial autocorrelation in the residuals. Such a correlation persists for different lags. There is clear evidence of non-normality in the residuals and of some type of heteroscedasticity for the majority of the equations. The Johansen procedure shows that asymptotic properties are preserved even in the presence of heteroscedasticity and non-normality; however, in small samples, there can be serious distortions of size and power in the tests.

We also performed the Johansen procedure to evaluate the existence of cointegration between the series for the system containing the rates for 1 , 2, 3, 6 and 12 months. The results are reported in Table 8 . The results of the trace test and the maximum eigenvalue test indicate the existence of at least 3 cointegration vectors at a level of $1 \%$. There may perhaps be a fourth relation; however, all of the p-values are lower than 17.5\%. The expectations hypothesis would suggest the presence of four relations. Because the specification tests for the model are not fully satisfactory, the results of the Johansen cointegration test should be analysed with the usual caution. Additionally, the presence of structural break alters the distribution for the trace statistic in an unknown way. 
TABLE 6. Estimated parameters based on model 2 - Database 1

\begin{tabular}{|c|c|c|c|c|c|c|}
\hline \multicolumn{7}{|c|}{ "Estimated Parameters } \\
\hline \multicolumn{7}{|c|}{ Regime1 } \\
\hline & $\overline{L i 01}$ & $\overline{L i 06}$ & $\overline{L i 12}$ & $\overline{L i 24}$ & Li36 & Constant \\
\hline Vector 1 & -1 & 1 & 0 & 0 & 0 & $-0.06 \%$ \\
\hline Vector 2 & -1 & 0 & 1 & 0 & 0 & $-0.24 \%$ \\
\hline Vector 3 & -1 & 0 & 0 & 1 & 0 & $-0.17 \%$ \\
\hline Vector 4 & -1 & 0 & 0 & 0 & 1 & $0.12 \%$ \\
\hline \multicolumn{7}{|c|}{ Load Matrix } \\
\hline Equation 1 & $\overline{c 3.47}$ & "-3.33 & 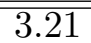 & 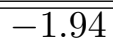 & & \\
\hline Equation 2 & 2.66 & -2.65 & 2.48 & -1.53 & & \\
\hline Equation 3 & 4.24 & -4.60 & 3.06 & -1.57 & & \\
\hline Equation 4 & 5.74 & -6.19 & 3.71 & -1.77 & & \\
\hline Equation 5 & 5.96 & -6.34 & 4.03 & -1.99 & & \\
\hline & Li01 & Li06 & Li12 & $L i 24$ & $L i 36$ & Constant \\
\hline Vector 1 & -1 & 1 & 0 & 0 & 0 & $-0.06 \%$ \\
\hline Vector 2 & -1 & 0 & 1 & 0 & 0 & $-0.24 \%$ \\
\hline Vector 3 & -1 & 0 & 0 & 1 & 0 & $-0.17 \%$ \\
\hline Vector 4 & -1 & 0 & 0 & 0 & 1 & $0.12 \%$ \\
\hline \multicolumn{7}{|c|}{ Load Matrix } \\
\hline Equation 1 & $\overline{1.53}$ & -1.07 & 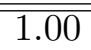 & -0.59 & & \\
\hline Equation 2 & 1.00 & -1.07 & 1.47 & -0.81 & & \\
\hline Equation 3 & 1.94 & -3.30 & 3.73 & -1.78 & & \\
\hline Equation 4 & 2.07 & -3.87 & 4.46 & -2.14 & & \\
\hline Equation 5 & 1.90 & -3.78 & 4.57 & -2.23 & & \\
\hline \multicolumn{7}{|c|}{ Regime 3} \\
\hline & $\overline{L i 01}$ & $\overline{L L i 06}$ & $\overline{L i 12}$ & Li24 & $\overline{c L i 36}$ & Constant \\
\hline Vector 1 & -1 & 1 & 0 & 0 & 0 & $-0.06 \%$ \\
\hline Vector 2 & -1 & 0 & 1 & 0 & 0 & $-0.24 \%$ \\
\hline Vector 3 & -1 & 0 & 0 & 1 & 0 & $-0.17 \%$ \\
\hline Vector 4 & -1 & 0 & 0 & 0 & 1 & $0.12 \%$ \\
\hline \multicolumn{7}{|c|}{ Load Matrix } \\
\hline$\overline{\text { Equation } 1}$ & "4.86 & -4.81 & 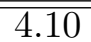 & -2.14 & & \\
\hline Equation 2 & 3.44 & -3.23 & 2.97 & -1.63 & & \\
\hline Equation 3 & 4.95 & -5.98 & 5.72 & -2.98 & & \\
\hline Equation 4 & 6.48 & -7.95 & 6.97 & -3.52 & & \\
\hline Equation 5 & 7.11 & -8.76 & 7.47 & -3.74 & & \\
\hline
\end{tabular}


Evaluating the existence of structural change in the Brazilian term structure of interest rate: evidence based on Hansen's cointegration models with structural break

TABLE 7. Specification tests for the VECM model - Database 02 .

\begin{tabular}{|c|c|c|c|c|c|}
\hline Equation & $\overline{L i 01}$ & $\overline{L i 02}$ & $\overline{L i 03}$ & 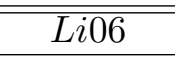 & $\overline{L i 12}$ \\
\hline Tests & \multicolumn{5}{|c|}{ Autocorrelation test order $1-7$} \\
\hline Distribution & $\mathrm{F}(7,130)$ & $\mathrm{F}(7,130)$ & $\mathrm{F}(7,130)$ & $\mathrm{F}(7,130)$ & $\mathrm{F}(7,130)$ \\
\hline Statistics & 2.3581 & 2.0769 & 2.1124 & 2.3446 & 2.3232 \\
\hline p-value & {$[0.0267]$} & {$[0.0504]$} & {$[0.0466]$} & {$[0.0275]$} & {$[0.0289]$} \\
\hline Tests & \multicolumn{5}{|c|}{ Portmanteau (12) } \\
\hline Distribution & $\chi^{2}(5)$ & $\chi^{2}(5)$ & $\chi^{2}(5)$ & $\chi^{2}(5)$ & $\chi^{2}(5)$ \\
\hline Statistics & 15.71 & 15.808 & 16.831 & 17.727 & 15.431 \\
\hline p-value & [0.0077] & 0.0074 & 0.0048 & 0.0033 & [0.0087 \\
\hline Tests & \multicolumn{5}{|c|}{ ARCH test - order 1 to 7} \\
\hline Distribution & $\mathrm{F}(7,159)$ & $\mathrm{F}(7,159)$ & $\mathrm{F}(7,159)$ & $\mathrm{F}(7,159)$ & $\mathrm{F}(7,159)$ \\
\hline Statistics & 0.26425 & 0.29416 & 0.5326 & 0.54397 & 0.58599 \\
\hline p-value & {$[0.9668]$} & {$[0.9554]$} & {$[0.8089]$} & [0.8001] & {$[0.7667]$} \\
\hline Tests & \multicolumn{5}{|c|}{ Heteroscedasticity Test } \\
\hline Distribution & $\mathrm{F}(70,102)$ & $\mathrm{F}(70,102)$ & $\mathrm{F}(70,102)$ & $\mathrm{F}(70,102)$ & $\mathrm{F}(70,102)$ \\
\hline Statistics & 5.4332 & 4.766 & 4.4392 & 3.6216 & 3.8526 \\
\hline p-value & 0.0000 & [0.0000] & {$[0.0000]$} & {$[0.0000]$} & {$[0.0000]$} \\
\hline Tests & \multicolumn{5}{|c|}{ Normality Test } \\
\hline Distribution & $\chi^{2}(2)$ & $\chi^{2}(2)$ & $\chi^{2}(2)$ & $\chi^{2}(2)$ & $\chi^{2}(2)$ \\
\hline Statistics & 135.19 & 111.07 & 90.796 & 81.354 & 48.053 \\
\hline p-value & [0.0000] & [0.0000] & [0.0000] & [0.0000] & [0.0000] \\
\hline
\end{tabular}

TABLE 8. Johansen cointegration test

\begin{tabular}{|c|c|c|c|c|c|}
\hline " Rank & Eigenvalue & $\overline{\text { Trace Test }}$ & p-value & $\begin{array}{c}\text { Maximum } \\
\text { Eigenvalue } \\
\text { Test }\end{array}$ & p-value \\
\hline 0 & 0.341 & 180.87 & {$[0.000]$} & 72.03 & {$[0.000]$} \\
\hline 1 & 0.311 & 108.85 & {$[0.000]$} & 64.53 & {$[0.000]$} \\
\hline 2 & 0.150 & 44.32 & {$[0.003]$} & 28.21 & {$[0.005]$} \\
\hline 3 & 0.076 & 16.1 & 0.173 & 13.65 & {$[0.110$} \\
\hline 4 & 0.014 & 2.45 & {$[0.691]$} & 2.45 & {$[0.690]$} \\
\hline
\end{tabular}


TABLE 9. Johansen cointegration test.

\begin{tabular}{|c|c|c|c|c|c|c|}
\hline \multicolumn{7}{|c|}{ Johansen } \\
\hline Statistics & \multicolumn{6}{|l|}{ 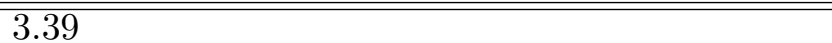 } \\
\hline Degree of Freedom & \multicolumn{6}{|l|}{4} \\
\hline Distribution & \multicolumn{6}{|c|}{ Chi-square } \\
\hline p-value & \multicolumn{6}{|l|}{$49.39 \%$} \\
\hline \multicolumn{7}{|c|}{ Estimated Parameters } \\
\hline \multicolumn{7}{|c|}{$\begin{array}{l}\text { Regime } 1 \\
\end{array}$} \\
\hline & Li01 & Li02 & Li03 & Li09 & $\overline{L i 12}$ & Constant \\
\hline Vector 1 & 1 & -1 & 0 & 0 & 0 & $0.10 \%$ \\
\hline Vector 2 & 1 & 0 & -1 & 0 & 0 & $0.21 \%$ \\
\hline Vector 3 & 1 & 0 & 0 & -1 & 0 & $0.54 \%$ \\
\hline Vector 4 & 1 & 0 & 0 & 0 & -1 & $1.07 \%$ \\
\hline \multicolumn{7}{|c|}{ Load Matrix } \\
\hline Equation 1 & -11.06 & 6.47 & -0.85 & 0.06 & & \\
\hline Equation 2 & -8.21 & 6.15 & -1.82 & 0.33 & & \\
\hline Equation 3 & -9.09 & 8.06 & -2.69 & 0.48 & & \\
\hline Equation 4 & -5.99 & 5.64 & -1.94 & 0.32 & & \\
\hline Equation 5 & -1.72 & 2.62 & -1.73 & 0.49 & & \\
\hline
\end{tabular}

Finally, we tested the hypothesis concerning the cointegration vectors. Assuming the existence of four cointegration relations, as suggested by the expectations hypothesis, we tested whether the estimated cointegration vectors satisfy the restrictions suggested by the spreads. The results are shown in Table 9, which show an asymptotic chi-squared distribution with four degrees of freedom. The null hypothesis is fully accepted. However, the same test performed for a sample reaching the end of 2001 produces a different result, which suggests that the conclusion is not robust for the sample used.

5.2.2. Hansen Model [13]. We estimated the Hansen model [13] using database 02. This contains the data for the periods of financial crises in Asia, Latin America, and Russia for the second half of 1990s. Because there is evidence of heteroscedasticity in the residuals, we opted to estimate a VECM whose pattern of heteroscedasticity is given by the DCC-GARCH multivariate model of volatility proposed by Engle [8]. The graph for the estimated volatilities for the various equations is presented in Figure 12. The volatility peaks are concentrated in the period of financial crises of the second half of the 1990s and around 2002. Beginning in 2005, the level of 

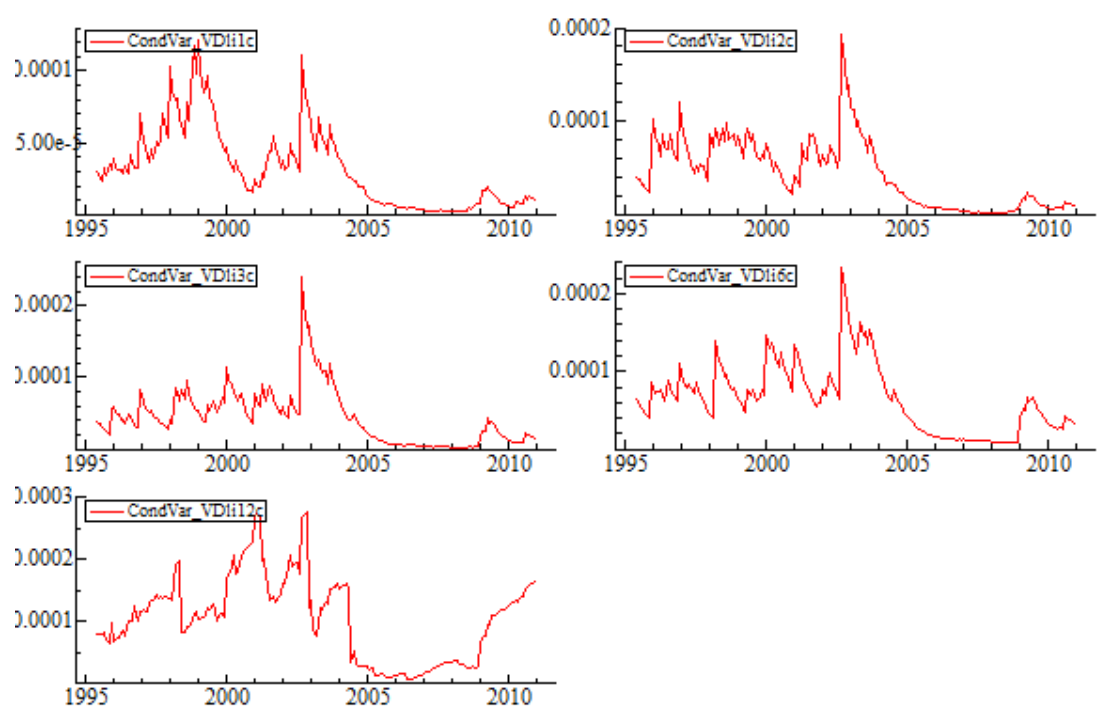

Figure 12. Evolution of the estimated long-term premium for various peaks.

volatility falls sharply for all rates. There is an increase in volatility at the end of the sample, most probably due to the sub-prime crisis of 2008 . The increase in volatility was very modest.

Table 10 presents the various estimated specifications for the data from database 2. The general model is that from specification number 5 . The others present some additional restrictions to the initial model, and all of them were embedded. Model 1 showed the greatest number of restrictions. We allowed 3 distinct regimes. The first began at the beginning of the sample and ended in 1998:12. The second regime began in 1999:1 and ended in 2002:12. The third regime began in 2003:1 and ended at the end of the sample in 2010:12.

Because all of the models are embedded, it is possible to test whether the restrictions imposed on the general model are valid based on a test of likelihood ratio with a chi-squared asymptotic distribution. The results of these tests are presented in Table 11. The tests suggest that models 1 to 3 are not good simplifications of the general model. In contrast, model 4 is acceptable at traditional levels of significance as a valid simplification, with 
TABle 10. Description of estimated specifications for the Hansen model

\begin{tabular}{|c|c|c|c|c|c|}
\hline \hline Model & $\begin{array}{c}\text { Cointegration } \\
\text { Vectors are: }\end{array}$ & Premium & $\begin{array}{c}\text { Load } \\
\text { Matrix }\end{array}$ & $\begin{array}{c}\text { Log } \\
\text { Likelihood }\end{array}$ & $\begin{array}{c}\text { Number of } \\
\text { Parameters }\end{array}$ \\
\hline 1 & spreads & $\begin{array}{c}\text { equal } \\
\text { between } \\
\text { regimes }\end{array}$ & $\begin{array}{c}\text { equal } \\
\text { between } \\
\text { regimes }\end{array}$ & 4828.65 & 154 \\
\hline 2 & spreads & $\begin{array}{c}\text { equal } \\
\text { between } \\
\text { regimes }\end{array}$ & unrestricted & 5060.96 & 194 \\
\hline 3 & unrestricted & unrestricted & 5065.37 & 202 \\
\hline 4 & $\begin{array}{c}\text { Short spreads in all regimes } \\
\text { and } \\
\text { Long spread in final regime }\end{array}$ & unrestricted & unrestricted & 5123.52 & 203 \\
\hline 5 & unrestricted & unrestricted & unrestricted & 5130.23 & 214 \\
\hline \hline
\end{tabular}

TABLE 11. Description of estimated specifications for the Hansen model

\begin{tabular}{|c|c|c|c|c|c|c|}
\hline Model & \multicolumn{3}{|c|}{ Mi against M2 } & \multicolumn{3}{|c|}{ Mi against M3 } \\
\hline$i$ & Statistics & $\begin{array}{l}\text { Degrees of } \\
\text { Freedom }\end{array}$ & p-value & Statistics & $\begin{array}{l}\text { Degrees of } \\
\text { Freedom }\end{array}$ & p-value \\
\hline $\begin{array}{l}1 \\
2 \\
3 \\
4\end{array}$ & 464.60 & 40 & $0.00 \%$ & $\begin{array}{c}473.43 \\
8.83\end{array}$ & $\begin{array}{c}48 \\
8\end{array}$ & $\begin{array}{c}0.00 \% \\
35.67 \%\end{array}$ \\
\hline Model & & 1 against $\mathrm{M} 4$ & & & against M5 & \\
\hline$i$ & Statistics & $\begin{array}{l}\text { Degrees of } \\
\text { Freedom }\end{array}$ & $\mathrm{p}$-value & Statistics & $\begin{array}{l}\text { Degrees of } \\
\text { Freedom }\end{array}$ & p-value \\
\hline$\overline{1}$ & $\overline{589.73}$ & 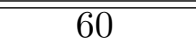 & (0.00\% & 603.15 & $\overline{660}$ & "0.00\% \\
\hline 2 & 125.13 & 20 & $0.00 \%$ & 138.55 & 20 & $0.00 \%$ \\
\hline 3 & 116.30 & 12 & $0.00 \%$ & 129.72 & 12 & $0.00 \%$ \\
\hline 4 & & & & 13.42 & 11 & $26.68 \%$ \\
\hline
\end{tabular}

a p-value of $26.68 \%$. The parameters of the long-term matrix estimated for the 3 regimes are given in Table 12 .

\subsection{Comparison of Results.}

5.3.1. Comparison of the results of the Hansen model [13] for the two databases. There is a sampling difference that may explain the difference in the 
Evaluating the existence of structural change in the Brazilian term structure of interest rate: evidence based on Hansen's cointegration models with structural break

TABle 12. Estimated Parameters based on model 4- Database 2 .

\begin{tabular}{|c|c|c|c|c|c|c|}
\hline \multicolumn{7}{|c|}{ Estimated Parameters } \\
\hline \multicolumn{7}{|c|}{ Regime1 } \\
\hline & Li01 & $\overline{L i 02}$ & $2 \mathrm{Li03}$ & Li09 & $\overline{L i 12}$ & Constant \\
\hline Vector 1 & -1 & 1 & 0 & 0 & 0 & $1.41 \%$ \\
\hline Vector 2 & -1 & 0 & 1 & 0 & 0 & $-7.19 \%$ \\
\hline Vector 3 & -1 & 0 & 0 & 1 & 0 & $-7.12 \%$ \\
\hline Vector 4 & -1 & 0 & 0 & 0 & 1 & $10.76 \%$ \\
\hline \multicolumn{7}{|c|}{ Load Matrix } \\
\hline Equation 1 & 2.37 & 0.55 & 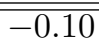 & (0.00 & & \\
\hline Equation 2 & 1.28 & -0.78 & 0.59 & -0.08 & & \\
\hline Equation 3 & 0.51 & -1.42 & 0.95 & -0.10 & & \\
\hline Equation 4 & 0.20 & -1.43 & 0.58 & -0.14 & & \\
\hline Equation 5 & -0.06 & -1.02 & 0.13 & -0.14 & & \\
\hline & & & & & & \\
\hline \multicolumn{7}{|c|}{ Regime 2} \\
\hline & $\overline{L L i 01}$ & Li02 & 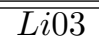 & Li09 & 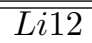 & Constant \\
\hline Vector 1 & -1 & 1 & 0 & 0 & 0 & $-1.18 \%$ \\
\hline Vector 2 & -1 & 0 & 1 & 0 & 0 & $0.20 \%$ \\
\hline Vector 3 & -1 & 0 & 0 & 1 & 0 & $-0.71 \%$ \\
\hline Vector 4 & 0.62017 & 0 & 0 & 0 & 1 & $-2.64 \%$ \\
\hline \multicolumn{7}{|c|}{ Load Matrix } \\
\hline 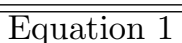 & $\overline{-2.24}$ & $\overline{11.66}$ & 0.39 & 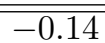 & & \\
\hline Equation 2 & -2.83 & 0.87 & 0.78 & -0.14 & & \\
\hline Equation 3 & -3.38 & 0.11 & 1.17 & -0.15 & & \\
\hline Equation 4 & -3.46 & -0.07 & 1.05 & -0.14 & & \\
\hline Equation 5 & -3.52 & -0.06 & 0.90 & -0.14 & & \\
\hline \multicolumn{7}{|c|}{ Regime 3} \\
\hline & $2 \mathrm{Li01}$ & $\overline{L L i 02}$ & Li03 & Li09 & $\overline{L i 12}$ & Constant \\
\hline Vector 1 & -1 & 1 & 0 & 0 & 0 & $-0.01 \%$ \\
\hline Vector 2 & -1 & 0 & 1 & 0 & 0 & $0.06 \%$ \\
\hline Vector 3 & -1 & 0 & 0 & 1 & 0 & $0.07 \%$ \\
\hline Vector 4 & -1 & 0 & 0 & 0 & 1 & $0.14 \%$ \\
\hline \multicolumn{7}{|c|}{ Load Matrix } \\
\hline "Equation 1 & 2.87 & $=0.34$ & $\overline{c-0.32}$ & "0.15 & & \\
\hline Equation 2 & 2.02 & -1.11 & 0.34 & 0.02 & & \\
\hline Equation 3 & 1.49 & -1.95 & 0.84 & -0.04 & & \\
\hline Equation 4 & 2.55 & -2.87 & 0.63 & 0.11 & & \\
\hline Equation 5 & 3.40 & -3.77 & 0.97 & -0.12 & & \\
\hline
\end{tabular}


results. For the model based on database 1, which does not contain the data for the years from 1995 to 1997, the no-arbitrage restriction for the long-term is loosely accepted, whereas such a restriction for database 2 is rejected. The estimated result based on the Hansen model suggests that there was not only a strong change in the risk premiums but also in the volatility.

5.4. A global consideration of the models: did the long-term risk premium vary? The Hansen model allows for the direct testing of the hypothesis of structural break, and for both of the databases some type of structural change was detected.

\section{Comparison with the literature}

6.1. Comparison with the literature. There is a broad literature on the term structure of interest rates, beginning with the classic studies by Campbell and Shiller [3] and Shiller [31]. In this study, we did not intend to provide a broad review of the international literature on the subject. Curthberston \& Nietzche [6] already performed this review. This study will limit itself to a few important references necessary for comparison with this paper. In Brazil, the study of term structure is relatively recent. Below, we review the conclusions of the most important studies performed for Brazil, and their conclusions are compared with the results of this study.

Lima and Issler [22] tested the expectations hypothesis for Brazil using swap data from BM\&F for various peaks based on the 30-day rate, similar to the one-month rate used for this study. The authors did not find evidence supporting the expectations hypothesis. They found evidence of a reversion to the mean in the spread with longer peaks. The authors estimate a VECM for pairs of interest rates. Their results are directly comparable with those obtained in this study. They report estimates of tests to determine whether the vector of the estimated cointegration can be interpreted as a spread. This hypothesis is not rejected at a $10 \%$ level. However, the authors do not report the estimated values for the long-term premium obtained based on this methodology.

Tabak and Andrade [33] tested the expectations hypothesis using the Shiller methodology [31] for daily data from the BM\&F with peaks at 1 , 2, 3, 6 and 12 months. They do not use the cointegration methodology in the form proposed by Johansen [15]. Therefore, the comparison with our results is not direct. The spread between the rate for 12 months and 1 month would have a premium of about 3\% for the period between 1995 and 2000. The premium is estimated based on the regression constant for a uni-equational model between the theoretical spread and the actual spread (Shiller [31]). 
Tabak and Gullien [32] use state-space models to estimate the risk premiums for peaks of 3 and 6 months. They allow the premium to vary over time with various specifications: stationary premium, non-stationary premium, and Markovian change. The authors' sample begins in 1999 and ends in 2005. The estimated risk premium is higher at the beginning of the sample and falls continuously until the middle of 2000. In the middle of 2002, the premium begins to rise sharply, with a peak in mid-2003, and then returns to small values statistically equal to zero. The estimated values are within the same order of magnitude as those estimated in the present study.

Brito et al. [2] test the expectations hypothesis with daily data from the BM\&F between 1996 and 2002. They use the traditional Shiller methodology [31]. The expectations hypothesis is rejected, and they find evidence of excessive reaction in the spreads. They also use the Johansen methodology to estimate multivariate models with pairs of rates. The results are reported in Table 2 on page 17 of the study for all combinations of spreads. They estimate an average premium of $6 \%$ for the spread of 1 year and 1 month, $5 \%$ for the spread of 6 months and 1 month, $3 \%$ for the spread of 3 months and 1 month, and 1\% for the rate of 2 months and 1 month. They find evidence of a growing premium for maturity similar to that found in this study.

Marçal and Valls Pereira [23] test the expectations hypothesis using the methodology of Johansen [15] and of Shiller [31]. The study differs from the applications of the Johansen methodology as performed in the Brazilian literature. The authors generally analyse pairs of rates and not a multivariate system with a set of rates. This type of approach was used in studies on the subject outside of Brazil. Examples include Anderson, Hall and Granger[1], Engsted and Tanggaard [9], Johnson [18] and Pagan, Hall and Martin [24]. In general, the hypothesis that the estimated vectors are given by spreads is rejected, which implies the non-validity of the long-term implications of the expectations hypothesis. Marçal and Valls Pereira [23] obtain similar results for Brazil with a sample between 1996 and 2001.

For international studies, Hansen [13] is the principal reference whose approach is directly comparable with the approach performed in this study. The author estimates the long-term premium for peaks of $3,6,9,12,60$ and 84 months based on the peak for 1 month. The values were estimated for 3 different periods: 1970:3 to 1979:9, 1979:10 to 1982:10 and 1982:11 to 1995:12. The values of the first and third regimes are very similar and lower than those prevailing in the second period. The premium of the spread between 12 months and 1 month varies between $0.9 \%$ and $1.05 \%$ per year. The values of the American term structure are similar to those obtained for the Brazilian structure only at the end of the sample, suggesting that the Brazilian term structure is moving toward an international standard, 
although the liquidity and longer premiums ( 5 and 7 years) analysed in Hansen are not yet observed.

Enders and Granger [7] estimate a VECM following the Johansen model, with the addition of a regime with abrupt transition (Threshold VECM) for a bivariate system with the FED Fund rate (short-term rate) and the ten-year rate for American public securities. They estimate a long-term premium of about $0.8 \%$. The sample covers the period from 1958 to 1994 .

6.2. Limitations of the Study and Possible Extensions. Seo [30] proposes an estimator with nonlinear least squares with a soft transition to estimate a cointegration model with abrupt change. Enders and Granger [7] estimate a model in which structural change is triggered by the spread exceeding a particular threshold. This is a nonlinear model with abrupt change; this path can be explored as an extension of this study, which has yet to be explored to a great extent in Brazil.

Another path that has not been extensively explored has to do with the utilisation of data concerning term securities indexed to inflation that are traded at the BM\&F. This extension has been attempted by Barr \& Campbell [4] for English data. The study by Vicente and Gullien [35] is an example of work in this area for Brazil.

Finally, it is important to study what explains the variation in the term of the risk premium and to what degree macroeconomic factors such as business cycles and inflation influence the Brazilian term structure and can predict such movements. This is the subject of a study by Fernandes Ribeiro and Valls Pereira [10].

\section{Conclusions}

This study sought to investigate the existence of structural change in the Brazilian term structure. Two databases were analysed based on multivariate models for cointegration with some type of structural change. There is evidence that the dynamics of the Brazilian term structure of interest rates underwent important changes during the period analysed, which ranged from 1995 to 2010.

The models estimated suggest that the premiums for maturity fell strongly beginning in 2002 and began to converge to values obtained in international studies. The events of the financial crises had strong impacts on the risk premiums as well as on the volatility of the rates. The developments following the sub-prime crisis of 2008 had more limited effects on the Brazilian term structure.

Transition from a regime in which premiums for maturity are higher to a regime in which such premiums are lower began around 2000, and the 
transition was not fully complete until 2005. It is suggested that macroeconomic events must have been important in the evolution of maturity premiums. In particular, in mid-1999, Brazil adopted a floating exchange regime with inflation goals and began implementing a project of fiscal adjustment and more intense public debt. The transition has been completed to the extent that inflation has been consolidated at lower levels and the external scenario has stabilised.

\section{References}

[1] Anderson, H. M.; Hall, A. D. e Granger, C. W. (1992) A Cointegration Analysis of Treasury Bill Yields. Review of Economics and Statistics, 74, 1, 116-126.

[2] Brito, R. D.; Duarte, A. J. M. A. e Guillen, O. T. C. (2004) Overreaction of yield spreads and movements of Brazilian interest rate. Revista de Econometria, 24, 1, 1-55.

[3] Campbell, J. e Shiller, R. J. (1991) Yield Spreads and Interest Rate Movements: A Bird's Eye View. Review of Economic Studies, 58, 419-514.

[4] Barr, D. F., e Campbell,J. Y. (1997) Inflation, real interest rates, and the bond market: a study of UK nominal and indexlinked government bond prices. Journal of Monetary Economics, 39, 3, 361-383.

[5] Cavaliere, G.; Rahbek, A. e Taylor, A. M. R. (2010) Testing for Co-Integration in Vector Autoregressions with Non-Stationary Volatility, Journal of Econometrics, 158, 1, 7-24.

[6] Cuthbertson, K. e Nitzsche, D. (2005) Quantitative Financial Economics. West Sussex: John Wiley \& Sons Ltd.

[7] Enders, W, e Granger, C. (1998) Unit-Root Tests and Asymmetric Adjustment with an Example Using the Term Structure of Interest Rates. Journal of Business \& Economic Statistics, 16, 304-11.

[8] Engle, R. (2002) Dynamic Conditional Correlation: A Simple Class of Multivariate Generalized Autoregressive Conditional Heterocedasticity Models. Journal of Business \& Economic Statistics, 20, 339-350.

[9] Engsted, T e Tanggard, C. (1994) Cointegration and th US term structure. Journal of Banking and Finance, 18, 167-181.

[10] Fernandes Ribeiro, P. e Valls Pereira, P. L. (2010) Economic cycles and term structure: application to Brazil, Texto para Discussão - EESP 259 .

[11] Gonzalo, J. e Pitarakis, J.-Y. (2005) Threshold effects in cointegrating relationships. Southampton: Department of Economics University of Southampton, Discussion papers in economics and econometrics, no. 0506. 
[13] Hansen, P. R. (2003) Structural changes in the cointegrated vector autoregressive model. Journal of Econometrics,114, 261-295.

[14] Hicks, J. (1946) Value and Capital. Oxford: Oxford University Press.

[15] Johansen, S. (1988) Statistical Analysis of cointegration vectors. Journal of Economic Dynamics and Control, 12, 2, 231-254.

[16] Johansen, S. (1995) Likelihood-based inference in cointegrated vector autoregressive models. Oxford: Oxford University Press.

[17] Johansen, S.; Mosconi, R. e Nielsen, B. (2000) Cointegration in the presence of structural breaks in deterministic trends. Econometric Journal, 1, 3, 216-249.

[18] Johnson, P. A. (1994) On the number of common unit roots in the term structure of interest rates. Applied Economics, 26, 815-820.

[19] Keynes, J. M. (1930) Treatise on Money. London; Mac Millan.

[20] Kurita, T. e Nielsen, B. (2004) Short-Run Parameter Changes in a Cointegrated Vector Autoregressive Model. Working Paper, University of Oxford.

[21] Kristensen, D. e Rahbek, A. (2007) Likelihood-Based inference in nonlinear error-correction models. CREATES Research Paper.

[22] Lima, A. M. e Issler, J. V. (2003) A hipótese das expectativas na estrutura a termo da taxa de juros no Brasil: Uma aplicação de modelos a valor presente. Revista Brasileira de Economia, 57, 4, 873-898.

[23] Marçal, E. F. e Valls Pereira, P. L. (2007) A Estrutura a Termo das Taxas de Juros no Brasil: testando a hipóteses de Expectativas. Pesquisa e Planejamento Econômico, 37, 1, 113-148.

[24] Pagan, A. R.; Hall, A. D. e Martin, V. (1996) Modelling the term structure. Handbook of Statistcs, 14, 91-118.

[25] Ripatti, A. e Saikkonen, P. (2001) Vector Autoregressive Processes with Nonlinear Time Trends in Cointegrating Relations. Macroeconomic Dynamics, 5, 577-597.

[26] Saikoonen, P. (2001-a) Stability Results for nonlinear Vector Autoregressions with an Application to a Nonlinear Error Correction Model. Journal of Econometrics, 127, 1, 69-81.

[27] Saikkonen, P. (2001-b) Consistent Estimation in Cointegrated Vector Autoregressive Models with Nonlinear Time Trends in Cointegrating Relations. Econometric Theory, 17, 2, 296-326.

[28] Saikkonen, P. (2001-c) Statistical Inference in Cointegrated Vector Autoregressive Models with Nonlinear Time Trends in Cointegrating Relations. Econometric Theory, 17, 2, 327-356. 
Evaluating the existence of structural change in the Brazilian term structure of interest rate: evidence based on Hansen's cointegration models with structural break

[29] Saikkonen, P. (2008) Stability of regime switching error correction models under linear cointegration. Econometric Theory, 24, 1, 294-318.

[30] Seo, M. (2007) Estimation of Nonlinear Error correction model. LSE Discussion Paper.

[31] Shiller, R. J. (1990) The term structure of interest rate. Em: B. M. Friedman e F. H. Hahn (Ed.). Handbook of Monetary Economics, volume 1. p.627-722, Ansterdam: North-Holland.

[32] Tabak, B. M. e Guillen, O. T. C. (2008) Characterizing the Brazilian Term structure of interest rates. Brazilian Central Bank Working Paper Series. Brasilia: Banco Central do Brazil.

[33] Tabak, B. M. e Andrade, S. C. (2001) Testing the Expectation Hypothesis in the Brazilian Term Structure of Interest Rate. Brazilian Central Bank Working Paper Series. Brasilia: Banco Central do Brazil.

[34] Tsay, R. S. (2010) Analysis of Financial Time Series, 3 edição. Chicago: John Wiley \& Sons.

[35] Vicente, J. V. M. \& Guillen, O. T. C. (2010) Do Inflation-linked Bonds Contain Information about Future Inflation? Brazilian Central Bank Working Paper Series. Brasilia: Banco Central do Brazil. 